carbon containing 0.035 per cent of hydrogen does not take up chlorine, sugar charcoal, with 0.07 per cent, does take it up.

The experiments with charcoal and sulphur showed the absorption of from 20 to nearly 47 per cent in charcoal containing much hydrogen and oxygen, while nearly pure amorphous carbon takes up but little sulphur. Professor Mixter regards the sulphur as chemically combined with the carbon, in his experiments, and cites Berzelius in support of this view.

\section{THE EARTH AS AN ELECTRICAL CONDUCTOR.}

BY A. F. MCKISSiCK, ALABAMA POLYTeChNiC INSTitute, AUbURN, ALA.

STEINHILL, at Munich in 1837 , was the first to discover that the earth might be used instead of a return wire, contact being made to the earth at the two ends by means of metal plates sunk in the ground. He discovered this while experimenting on the Nürnberg. Fürther railroad for the purpose of determining whether the track could be used for telegraphic purposes. He noticed that the current passed from one rail to the other and the idea to use the ground as a return circuit occurred to him, which he afterwards found to be perfectly feasible. The earth is almost universally used as the return circuit in telephone and telegraph lines. While it is true that in the former a complete metallic circuit is sometimes found, it is not on account of the failure of the earth to conduct the current but for the purpose of diminishing the induction, caused by the presence of electric light and power circuits.

The earth-plates are made of zinc or copper and are sunk in moist earth, in a spring, or in the bed of a river. It has been generally considered that the earth offers no resistance at all as its cross-section is so large, although its specific resistance may be very high. While the resistance of the earth may be neglected when we have to deal with telephone and telegraph circuits, we must consider its resistance when it is to be used for conducting currents of large volume.

The element of danger to life and property forbids its use as a return in commercial lighting and motor circuits.

In street railway circuits, however, the earth is used partly as a return. It has been found that the earth alone, as a general rule, offers too much resistance, so that it is now almost the universal custom to use in connection with the earth the rails bonded together and also a bare copper wire. I had occasion during the past year to notice very closely this resistance in installing a motor at the experiment station of the A. and M. College of Alabama. I had expected to use the earth as a return, but owing to the very high resistance had to abandon this idea. It was with the idea of finding out how much the resistance of the earth near this motor was, that the following experiments were made.

An earth-pit was dug six feet deep, eight feet long, and two feet wide, at each end of the line running from generator at college to motor at experiment station. This line is by measurement three thousand feet long. A plate of copper, seven by two feet, and a plate of tin of came dimensions, soldered to a No. $0000 \mathrm{~B}$ and $\mathrm{S}$ wire were used as the earth-plate at each end. The plates were packed firmly with charcoal and iron filings and the pit filled with old iron. The water rose in one of the pits to a depth of two feet. With all connections soldered, the resistance measured by a Wheatstone bridge was found to be $102 \mathrm{ohms}$. supposing the earth connection was not a good one at each end of the line, an additional earth connection at each end was made by sinking a large piece of iron in a well. With this additional connection there was no appreciable difference in the resistance. Connections to the earth were then made at different distances from the college by connecting one end of a wire to the overhead wire, the other end soldered and tied to a piece of iron six feet long, driven down flush with the ground. These distances were respectively $500,1,000,1,500,2,000$, and 2,500 feet from the college. These connections were made at different times, always removing an earth connection when its resistance had been meas. ured. The resistances in the same order were $307,567,153,707$, and $217 \mathrm{ohms}$. The comparatively small resistances of stations
3 and 5 are probably explained by the fact that they were located near branches (small streams).

From these results we may conclude that the resistance of the earth is a very unknown quantity, and the assumption that the resistance of the earth can be neglected in any soil is an unsafe one when the object in view is to transmit currents without very much loss.

\section{A VALUABLE FLORIDA DEPOSIT.}

BY THOS. R. BAKER, PH.D.

THERE occurs near Bartow, Fla., and at other points as far south as Haines City a geological deposit which has recently been found to be very valuable as a material for covering the sandy side-walks and streets of Florida towns. It is popularly known in South Florida by the name "clay," but consists essentially of sand, clay, and oxide of iron, the proportions of which, determined by chemical analysis, are given in the following table:-

$$
\text { Per cent. }
$$

Moisture...................... 4.20

Silica.......................... 6903

Aluminum silicate................. 18.21

Iron oxide.........................

Calcium carbonate .................. Trace.

Geologically considered, the deposit is a sandstone rock, and, although it has to be quarried from its bed, it almost completely disintegrates in the quarrying, and needs no further preparation to fit it for the use to which it is applied. It is of a reddish color, due to the presence of oxide of iron.

The material is simply spread over the side-walk or street to which it is to be applied to the depth of several inches, and then sprinkled with water, and rolled with a heavy roller. After being walked upon and driven over for a short time it becomes very compact, and fully as hard as it is in its native bed.

The most valuable constituent of this material, when used as a covering for roads, is undoubtedly the oxide of iron, which acts as a cement, rendering the material capable of becoming compact and hard. That the iron serves this purpose was verified by removing it from the compound, and subjecting the mixture of the remaining constituents to tests that had been applied to the original material.

The adaptation of this deposit to the improvement of roads was first brought to notice by the South Florida and other railroad companies, who used it for the improvement of railroad crossings, drive-ways about stations, etc., and the first extensive use made of it for streets and side-walks was by the city of Orlando about a year ago. It has given excellent satisfaction in Orlando, nothing having been done for the place for years that has so improved it. It has been the means of converting streets so sandy that travel over them was very slow and difficult into drive-ways over which travel is easy and pleasant. Now, on Orlando streets, vehicles and horses' hoofs have the familiar rattle and thud that are heard when driving over a macadamized road. It is the opinion of those who have studied the subject that geological deposits like the one here described are of very rare occurrence.

\section{NOTES AND NEWS.}

THE next meeting of the Australian Association for the Advancement of Science will be held in Adelaide, South Australia, commencing on September 25th, 1893. The meeting in Adelaide will be presided over by Ralph Tate, F.L.S., F.G.S., professor of natural science at the University of Adelaide. At the time fixed for the meeting, South Australia will be at its best. There is no better time at which to visit Australia than when spring is merging into summer. To naturalists, this time of year is specially attractive, and these may be reminded that at the meeting of the Association they will come into contact with men of like tastes from all parts of Australia. Should visitors wish to prolong their trip, they will do well to visit during the months of October and November the principal objects of interest in the mainland, and in December, January, and February to pass on to New Zealand and Tasmania. 